\title{
Anterior cruciate ligament injury/reinjury in alpine ski racing: a narrative review
}

This article was published in the following Dove Press journal:

Open Access Journal of Sports Medicine

30 March 2017

Number of times this article has been viewed

\section{Matthew J Jordan' \\ Per Aagaard ${ }^{2}$ \\ Walter Herzog'}

'Human Performance Laboratory, The University of Calgary, Calgary, AB, Canada; ${ }^{2}$ Department of Sports Science and Clinical Biomechanics, SDU Muscle Research Cluster (SMRC), University of Southern Denmark, Odense M, Denmark
Correspondence: Matthew J Jordan Canadian Sport Institute Calgary, 2500 University Drive NW, Calgary, AB T2N IN4, Canada

Tel +l 4037144655

Email mjordan@ucalgary.ca
Abstract: The purpose of the present review was to: 1) provide an overview of the current understanding on the epidemiology, etiology, risk factors, and prevention methods for anterior cruciate ligament (ACL) injury in alpine ski racing; and 2) provide an overview of what is known pertaining to ACL reinjury and return to sport after ACL injury in alpine ski racing. Given that most of the scientific studies on ACL injuries in alpine ski racing have been descriptive, and that very few studies contributed higher level scientific evidence, a nonsystematic narrative review was employed. Three scholarly databases were searched for articles on ACL injury or knee injury in alpine ski racing. Studies were classified according to their relevance in relation to epidemiology, etiology, risk factors, and return to sport/reinjury prevention. Alpine ski racers (skiers) were found to be at high risk for knee injuries, and ACL tears were the most frequent diagnosis. Three primary ACL injury mechanism were identified that involved tibial internal rotation and anteriorly directed shear forces from ski equipment and the environment. While trunk muscle strength imbalance and genetics were found to be predictive of ACL injuries in development-level skiers, there was limited scientific data on ACL injury risk factors among elite skiers. Based on expert opinion, research on injury risk factors should focus on equipment design, course settings/speed, and athlete factors (eg, fitness). While skiers seem to make a successful recovery following ACL injury, there may be persistent neuromuscular deficits. Future research efforts should be directed toward prospective studies on ACL injury/reinjury prevention in both male and female skiers and toward the effects of knee injury on long-term health outcomes, such as the early development of osteoarthritis. International collaborations may be necessary to generate sufficient statistical power for ACL injury/reinjury prevention research in alpine ski racing.

Keywords: knee injury, return to sport, injury prevention, knee biomechanics, ACL reinjury

\section{Introduction}

Alpine ski racing is considered an extreme sport, and skiers are at increased risk for traumatic injury consequent to the high speeds, high external forces, and the unpredictable competitive environment. ${ }^{1-4}$ The knee joint and more specifically the anterior cruciate ligament (ACL) are frequently injured during alpine ski racing. ${ }^{1-6}$ This is particularly concerning as ACL injury in young adulthood increases the risk of developing symptomatic knee joint osteoarthritis (OA) later in life. ${ }^{7}$ This places increased importance on ACL injury prevention and ensuring ACL injured skiers are fit to return to sport given the potential for persistent neuromuscular deficits consequent to ACL injury. ${ }^{8}$

Injury prevention is described by van Mechelen et $\mathrm{al}^{9}$ as a four-stage model. First, the injury incidence is established. Second, injury mechanisms and etiology are described. 
Injury prevention strategies are then introduced followed by a return to stage one to evaluate the effects on injury incidence. The causation of sport related injury is multifactorial. ${ }^{10}$ Risk factors are classified as intrinsic to the athlete (eg, fitness, age, gender) and extrinsic to the athlete (eg, environmental factors, equipment factors). Of importance is identifying potential modifiable intrinsic risk factors that can be mitigated through exercise based (training) intervention programs. ${ }^{11}$ Intrinsic modifiable risk factors related to ACL injury include knee control particularly with respect to valgus loading, ${ }^{12-15}$ hamstring/quadriceps muscle strength, ${ }^{16}$ and quadriceps vs hamstring coactivity. ${ }^{16}$ Neuromuscular injury prevention training programs have also proved successful for reducing the incidence of ACL injuries in other high-risk sports. ${ }^{14,17-19}$ Following ACL reconstruction, 2 years may be required for full recovery of hamstring/quadriceps strength and knee function to preinjury values. ${ }^{20}$ Further, young athletes with previous ACL reconstruction are at a significantly elevated risk of ACL reinjury compared to their noninjured counterparts. ${ }^{21}$ This highlights the importance of identifying modifiable risk factors not only for primary ACL injury prevention but also for secondary ACL reinjury prevention. ${ }^{8}$

The scientific literature on sport-related injury prevention and sport-specific ACL injury prevention research in other athlete populations may provide a helpful framework for future ACL injury/reinjury prevention research in alpine ski racing. Given the high prevalence of ACL injuries among alpine ski racers, it is also important to review the current scientific evidence on ACL injury/reinjury prevention specific to alpine ski racing. Thus, the primary purpose of the present review was to provide an overview of the scientific literature on the epidemiology, etiology, risk factors, and prevention methods related to ACL injury in alpine ski racing. A secondary objective was to provide an overview of the current knowledge on ACL reinjury and return to sport after ACL injury in alpine ski racing.

\section{Methodology}

Recently, a nonsystematic narrative review was conducted on the general topic of injury prevention in elite alpine ski racing. ${ }^{22}$ Given the paucity of studies contributing higher level evidence on ACL injury in alpine ski racing, and a larger emphasis on qualitative research studies, a nonsystematic narrative review was deemed the most appropriate methodology for the present review. Thus, in contrast to the goal of a systematic review that addresses a specific research question, we aimed to provide a summary of the relevant scientific literature at hand and to include a discussion on future considerations.
A literature search was conducted in three scholarly databases (PubMed, SPORTDiscus, and MEDLINE) using the search terms: "alpine skiing AND ACL" to identify relevant scientific articles. To ensure that we identified as many studies as possible with relevance to the present topic, a second search was performed using the search terms: "alpine skiing AND knee injury". The abstracts of these studies were reviewed, and only papers written in English and published between 1991 and the time of this review were included. Additional inclusion criteria were studies examining alpine ski racers (including development level alpine ski racers and/ or top-ranked alpine ski racers), and ACL injury, ACL reinjury, or return to sport after ACL injury. While the primary focus of this paper was on ACL injuries in alpine ski racing, we also included papers that broadly evaluated knee injuries in alpine ski racers given the limited amount of research that exists in this area. Papers that focused on recreational alpine skiers were not considered. After the literature search was completed, the reference sections of these papers were crossreferenced to identify additional articles of interest. Figure 1 provides an overview of the data retrieval/analysis for identifying relevant scientific articles of interest. Papers were classified into four ACL injury categories in accordance with the model developed by van Mechelen et $\mathrm{al}^{9}$ as: epidemiology, etiology, injury risk factors, and injury prevention methods. Those that focused on specific biomechanical or neuromuscular factors related to ACL injury were also included in the injury etiology category. Finally, those that focused on neuromuscular function after ACL injury, return to sport after ACL injury, and ACL reinjury were identified and categorized. To provide discussion around future directions for scientific research on ACL injury/reinjury prevention in alpine ski racing, studies from other athlete populations were included when relevant throughout this paper.

\section{Results}

\section{Epidemiology of $A C L$ injuries}

Initial studies on the prevalence of ACL injuries among alpine ski racers and professional skiers have been limited to retrospective research designs on single teams and organizations. ${ }^{2,5,6}$ Stevenson et $\mathrm{al}^{5}$ conducted a retrospective review on the prevalence of ACL injuries in 404 collegiate alpine ski racers. ACL tears accounted for nearly 50\% of all knee injuries, hence representing the major type of knee joint injury in this group of ski racers (Table 1). A total of $13 \%$ of study participants reported an ACL injury, with a significantly greater number of ACL injuries occurring in 


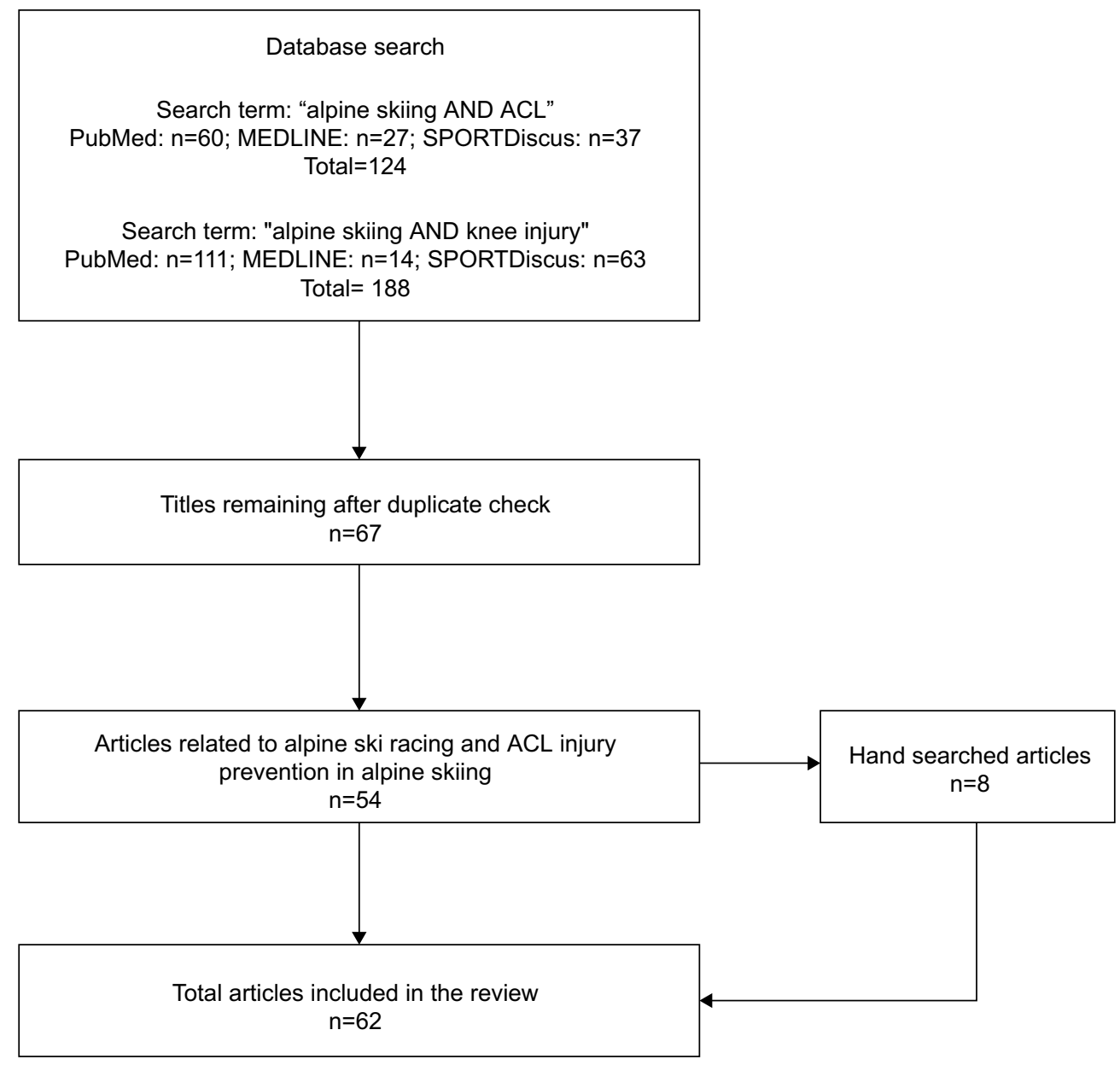

Figure I Flow diagram for identifying articles of interest in the present review. Abbreviation: $\mathrm{ACL}$, anterior cruciate ligament.

female skiers $(22 \%)$ compared to males $(7 \%) .^{5}$ Twentytwo percent of skiers required a subsequent ACL revision surgery. ${ }^{5}$ In contrast, a study evaluating the prevalence of ACL injuries in a large group $(n=7,155)$ of professional ski patrols found no difference in ACL injury rates between males and females. ${ }^{6}$

Pujol et al retrospectively analyzed a database of 379 French alpine ski racers and found no difference in ACL injury rates between males and females as well. ${ }^{3}$ However, female skiers were younger ( $21 \pm 3.9$ years) than males ( $23 \pm 3.9$ years) when ACL injury was sustained (Table 1$){ }^{2}$ Twenty-eight percent of skiers sustained at least one ACL injury, $19 \%$ of ACL injured skiers sustained a second ACL injury to the same knee, and $30 \%$ of these skiers sustained contralateral ACL injury. ${ }^{2}$ Additionally, the prevalence of ACL injury was highest among skiers with a top-30 world ranking compared to lower ranked skiers.

The need for improved injury surveillance led the International Ski Federation (FIS) to implement a systematic Injury
Surveillance System (ISS) starting in 2006., ${ }^{1,2,4,23}$ Injuries during FIS World Cup competitions were documented using yearly retrospective interviews with athletes, coaches, and medical staff members from ten countries (Table 1). ${ }^{1}$ The absolute injury rate in training and competition was expressed as the number of injuries per 100 athletes per season. Relative injury rates were determined for the number of injuries occurring only during World Cup and World Championship competition and were expressed as the number of injuries per 1,000 runs. The knee was the most commonly injured body part (35.6\% of all injuries), and 54\% of knee injuries resulted in more than 28 days lost from sport. ${ }^{1,4}$ ACL injury was the most frequent and specific diagnosis, representing $14 \%$ of all injuries. ${ }^{1}$ The absolute injury rate was $5 \mathrm{ACL}$ injuries per 100 athletes per season and the relative knee injury rate was 3.2 per 1,000 runs. Like the findings of Pujol et al, ${ }^{3}$ the relative injury rate was not different between elite male and female ski racers. ${ }^{1}$ However, there was an increased risk of knee injury in Downhill (Relative Risk: Downhill $=1.84$ ) compared to the 
Table I Summary of study designs and ACL injury statistics for studies conducted with alpine ski racers

\begin{tabular}{lllll}
\hline Study design & Study population & ACL injury statistics & ACL reinjury statistics & Female vs male \\
\hline Retrospective analysis of survey & I,0I0 surveys sent; 404 & Injury prevalence: $13 \%$ & Bilateral injury prevalence & Females at elevated risk \\
responses from collegiate-level & respondents; F: $n=202 ;$ & (overall); 22\% (F); 7\% (M)* & not reported & for injury (relative risk \\
alpine ski racers (response & M: $n=202$ & & Ipsilateral revision & ratio females vs \\
rate $=40 \%)^{5}$ & Skiers reporting ACL & & prevalence: 22\% (overall); males =3.I)* & 27\% (F); I3\% (M) \\
& injury: $n=54 ; \mathrm{F}: \mathrm{n}=36 ;$ & &
\end{tabular}

25-year retrospective analysis of a National program database of elite and nationally ranked alpine ski racers (I,836 skier-seasons) $)^{3}$

Yearly retrospective interviews with 10 National team programs competing in FIS World Cup competitions, conducted over two seasons to evaluate all injury types (response rate $=100 \%)^{2}$

Yearly retrospective interviews with 10 National team programs competing in FIS World Cup competitions, conducted over six seasons (response rate not indicated $)^{26}$

10-year retrospective analysis of medical records from a development alpine ski racing program $^{27}$

Retrospective interviews with a development alpine ski racing program conducted over $2 \times / y r$ over 2 seasons ${ }^{29}$
Skiers in database: $n=379$;

$F: n=188 ; M: n=191$

Skiers suffering at least one $\mathrm{ACL}$ reconstruction: $\mathrm{n}=105 ; \mathrm{F}: \mathrm{n}=53 ; \mathrm{M}: \mathrm{n}=52$ $A C L$ injuries: $n=157$

Total interviews
conducted: $n=521$;
F: $n=229 ; M: n=292$
Total number of injuries
reported: $n=191$
ACL injuries: $n=26$

Total interviews conducted: $n=1,593$; F: $n=708 ; M: n=885$ Total number of injuries reported: $\mathrm{n}=577$ ACL injuries: $\mathrm{n}=26$

Total number of skiers: $\mathrm{n}=370 ; \mathrm{F}: \mathrm{n}=175 ; M: \mathrm{n}=195$ $A C L$ injuries: $n=57$; F: $n=39 ; M: n=18$

Total number of skiers interviewed: $\mathrm{n}=105$; F: $n=43 ; M: n=6$ I ACL injuries: $n=14$
Injury prevalence: $28 \%$ (overall); $28 \%(\mathrm{~F}) ; 27 \%$ (M) Absolute injury rate: $5.7 / 100$ skier-seasons (overall); 6.5/100 skierseasons (F); 5.4/100 skierseason (M)

Injury prevalence: $5 \%$ (overall); $14 \%$ of total injuries reported

Absolute injury rate: $5 / 100$ skiers/season ${ }^{\mathrm{a}}$

Relative knee injury rate: 3.2/I,000 runs; $2.6 / 1,000$ runs $(F) ; 3.7 / I, 000$ runs $(M)^{b}$

Absolute injury rate: 5.4/100 skiers/season (F); 5.5/100 skiers/season (M) Relative injury rate: I.2/I,000 runs (F); I.7/I,000 runs (M)

Injury prevalence: I5\% (overall); 22\% (F); $9 \%$ (M) Females 19 years of age at highest risk for injury Injury prevalence: $13 \%$ (overall); I2\% (F); I5\% (M)
Bilateral injury prevalence: $30.5 \%$ (overall); $34 \%(F)$; $27 \%$ (M) Ipsilateral $A C L$ revision prevalence: 19\% (overall); 19\% (F); 19\% (M)

Bilateral $A C L$ injuries and $A C L$ revisions not reported reported

Bilateral $A C L$ injuries and $A C L$ revisions not reported

\section{Bilateral $A C L$ injuries and $A C L$ revisions not reported}

Bilateral $A C L$ injuries and $A C L$ revisions not reported
No difference found between females and males

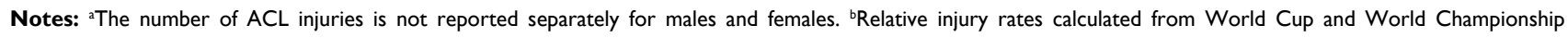
competitions. Data were reported only for knee injuries and not $A C L$ injuries. *Statistically significant difference, $P<0.05$.

Abbreviations: M, Male; F, Female; ACL, anterior cruciate ligament; FIS, International Ski Federation.

other events (ie, Relative Risk: Slalom =1.43; Giant Slalom $=0.90$, Super Giant Slalom $=1.05){ }^{1}$

The consistent observation of no sex-differences in ACL injury rates among elite alpine ski racers is unique as it is well established that female athletes are typically at increased risk for ACL injury compared to male athletes in other high-risk sports. ${ }^{24,25}$ A 6-year study using the FIS ISS comparing injury rates between male and female elite alpine ski racers reported no sex differences in the absolute ACL injury rates (Males: 5.5 ACL injuries/100 athletes/ season; Females 5.4 ACL injuries/100 athletes/season) or relative ACL injury rates (Males: 1.7 ACL injuries/1,000 runs; Females: 1.2 ACL injuries/1,000 runs) (Table 1). ${ }^{26}$ Consistent with previous reports, the highest risk for knee injuries was in the speed events compared to the technical events. $^{26}$

However, sex differences in ACL injury rates appear to exist in young ski racers (Table 1). ${ }^{27,28}$ A 10 -year study evaluating risk factors for ACL injuries in young ski racers between 14 and 19 years of age found females to be at increased risk for ACL injury compared to males (FemaleMale Risk Ratio: 2.3) ${ }^{27}$ Female skiers 19 years of age were at the highest risk for ACL injury followed by female skiers 17 years of age. Additionally, while knee injuries are the most common injury type among elite alpine ski racers, there are mixed findings with respect to adolescent skiers. ${ }^{27-30} \mathrm{~A}$ 2-year study including 104 young ski racers reported ACL tears to be the third most common injury preceded by lower 
back pain and nontraumatic knee pain. ${ }^{29}$ Conversely, a 5-year study including 431 Swedish adolescent alpine ski racers reported knee injuries to be the most common injury type. ${ }^{30}$

\section{$A C L$ injury mechanisms and etiology}

There is limited scientific data on the neuromuscular factors that contribute to ACL injury in elite alpine ski racing. Thus, related biomechanics research may provide an indication of potential neuromuscular contributors to the ACL injury mechanisms. The ACL resists anteriorly directed shear and internal rotation forces applied on the tibia relative to the femur. $^{31-33}$ Internally developed forces from the quadriceps muscles may strain the ACL in the distal range of motion close to full knee extension, ${ }^{33-35}$ while the hamstring muscles act as an ACL synergist by producing a posteriorly directed shear moment on the tibia. ${ }^{33,36,37}$ Both the equipment and physical demands of alpine skiing may expose the knee joint to high levels of external loading that can strain the ACL, thereby causing injury. ${ }^{32,38-42}$ Based on observations in five Canadian elite alpine ski racers, $\mathrm{McConkey}^{41}$ proposed an ACL injury mechanism involving combined anterior shear loading on the knee from a passive external force imparted on the tibia from the ski boot (ie, boot-induced anterior drawer) and an active internal shear force from a strong quadriceps muscle contraction that occurred as the skier attempted to recover from a back-weighted, unbalanced jump landing.

Tibial internal rotation forces are implicated in most skispecific ACL injury mechanisms. ${ }^{38}$ Hame et $\mathrm{al}^{32}$ attempted to replicate ski-specific ACL injury mechanisms and evaluated the effects of tibial internal/external rotation torque at four knee joint flexion angles on ACL strain in 37 cadaveric knee specimens. ACL strain was greatest at $0^{\circ}$ of knee flexion and in forced hyperflexion in combination with tibial internal rotation torque. ${ }^{32}$ With regard to the amount of ACL strain during alpine skiing, the knee flexion angle appears to be of particular importance. ${ }^{43,44}$ Specifically, at deeper angles of knee flexion, the knee joint geometry and lines of action for the quadriceps and hamstring muscles lend toward decreased anterior shear forces and less ACL strain. ${ }^{33,43,44}$ Landing back weighted following a jump may not per se be sufficient to load the ACL. ${ }^{43,44}$ However, an asymmetrical ski jump landing alongside a strong eccentric quadriceps contraction may generate a sufficiently large knee joint moment and high resultant anterior shear forces to cause ACL injury. ${ }^{43-45}$ The trunk inclination angle in jump landings is also of importance for minimizing ACL strain. ${ }^{46}$ This highlights the importance of technique and tactics in a failed landing alongside an imbalance in the active muscle forces as potential contributors to noncontact
ACL tears in alpine skiing. ${ }^{44,45}$ In fact, trunk orientation along with ankle, knee, and hip joint angles accounted for $88 \%$ of the variance in peak ACL force. ${ }^{46}$ Additionally, equipment factors including ski bindings ${ }^{39-42,47}$ and use of a stiffer ski boot are thought to increase anterior shear forces on the tibia during jump landings. ${ }^{48}$

A rare and accidental recording of a single skier who suffered an ACL injury while participating in a study evaluating muscle activity patterns and kinematics of alpine ski jump landings provides an indication of the kinematic and muscle activity changes associated with an acute noncontact ACL injury in alpine skiing. ${ }^{49}$ The quadriceps vs hamstring muscle activity and kinematic changes preceding/following the clapping period (ie, the time point when the tails of the skis contacted the snow to the time point when the full length of the skis were in contact with the snow) were measured. ${ }^{49}$ Additional parameters included the clap angle or the angle of the skis relative to the slope of the hill at the initial point of contact and the duration of the clap period. Compared to the noninjured study participants, the subject suffering an ACL tear landed in a slightly more backward position, had a shorter clap period duration ( $40 \mathrm{~ms}$ vs $95 \mathrm{~ms}$ for the reference group), a smaller clap angle ( $3^{\circ}$ vs $31^{\circ}$ for the reference group), demonstrated a lesser spatial change in the center of mass throughout the clap period, and displayed relatively less hamstring muscle activity in the injured limb compared to the noninjured limb during the postclap period. ${ }^{49}$ It was speculated that the smaller clap angle and clap period duration resulted in greater angular acceleration of the ski boot, and thus a greater anteriorly directed shear force on the tibia. ${ }^{49}$ Additionally, the shorter clap duration may have decreased the time required for adequate protective activation of the hamstring/quadriceps muscles, prompting an analysis of rapid force capacity (rate of force development: RFD) strength ratios (H/Q Ratio) in alpine downhill skiers ${ }^{50}$ and other athletes at risk for ACL injury. ${ }^{51}$

In other high-risk sports for ACL injury, ACL injury mechanisms have been identified through video analysis. ${ }^{52,53}$ Using a similar approach, Bere et $\mathrm{al}^{54}$ analyzed video recordings from 20 elite alpine ski racers who sustained ACL injuries during competition. All but one of the ACL injuries occurred during skiing. ${ }^{54}$ Three main noncontact ACL injury mechanisms were identified by Bere et al. ${ }^{54}$ The slip-catch mechanism occurred most frequently (50\% of cases) and happened while skiing (typically during a turn).$^{54}$ Pressure and snow contact was lost on the outer ski. Upon regaining contact with the snow, the ski caught causing a combination of rapid knee joint flexion, tibial internal rotation, and knee 
valgus. The second injury mechanism, the dynamic snow plow, occurred in 3/20 (15\%) of all ACL injuries. ${ }^{54}$ In this condition, the skier was caught out of balance in a backward position and had an asymmetrical interlimb weighting. The unweighted ski drifted away from the skier placing the skier in a split position. The ski rolled from the outer edge to the inner edge, caught the snow, and forced the knee into valgus and tibial internal rotation. The final injury mechanism, landing back weighted, occurred in 4/20 (20\%) of all ACL injuries. ${ }^{54}$ Here, the skier gets out of balance with the body mass moving backward during the landing. The tails of the skis contacted the snow first with a large clap angle and an extended knee joint angle. The proposed specific injury mechanism was a combination of tibiofemoral compression and anterior shear on the tibia as the skier attempted to recover from the back weighted position. ${ }^{54}$

The study performed by Bere et $\mathrm{al}^{54}$ provides new perspectives on potential ACL injury mechanisms for elite alpine ski racers. Notably, the dynamic snow plow and the slip-catch mechanisms occurred in 13/20 (65\%) cases during downhill skiing, ${ }^{54}$ and involved a combination of rapid knee joint flexion, tibial internal rotation, and knee valgus loading in a short time frame $(60 \mathrm{~ms}) .{ }^{55}$ These injury mechanisms are similar to the phantom foot mechanism that typically is observed in recreational alpine skiers. ${ }^{38}$ Tibial internal rotation appears to be a key loading factor in noncontact alpine skiing ACL injuries $^{32,53}$ and tibial rotation forces may be increased with skis that have a small turning radius (ie, more aggressive self-steering skis). ${ }^{56-59}$

\section{$A C L$ injury risk factors}

\section{Athlete risk factors}

There is limited scientific data on risk factors for ACL injury in elite alpine ski racing but of interest are risk factors both internal and external to the athlete and modifiable risk factors that can be addressed through neuromuscular training programs. ${ }^{10,12,14,17-19,60,61}$ A 10-year prospective study evaluated the relationship between physical fitness and ACL injury risk in young competitive ski racers and found that trunk (core) strength was a significant predictor of ACL injury (Table 2). ${ }^{27}$ Specifically, skiers who suffered from ACL injury demonstrated diminished core strength compared to noninjured skiers along with a suboptimal trunk flexion to trunk extension strength ratio. However, none of the additional fitness parameters obtained were associated with ACL injury risk. Additionally, young female alpine ski racers were found to be at increased risk for ACL injury compared to their male counterparts. ${ }^{27}$ While female athletes are at higher risk for sustaining noncontact ACL injury across many sports, ${ }^{24}$ there are no sex differences found among elite alpine ski racing competitors competing at the World Cup level. ${ }^{1,26}$

Table 2 Summary of studies conducted on alpine ski racers evaluating risk factors for ACL injury, injury prevention interventions, and the resulting effects on $A C L$ incidence

\begin{tabular}{|c|c|c|c|c|}
\hline Study design & Study population & $A C L$ injury risk factor & Injury prevention strategy & $\begin{array}{l}\text { Effect on } \\
A C L \text { injuries }\end{array}$ \\
\hline $\begin{array}{l}\text { 10-year retrospective analysis } \\
\text { to evaluate relationship } \\
\text { between fitness testing and } \\
\mathrm{ACL} \text { injuries (testing conducted } \\
3 \times / y r) .{ }^{27}\end{array}$ & $\begin{array}{l}\text { Total number of skiers: } \\
n=370 ; F: n=175 ; M: n=195 \\
A C L \text { injuries: } n=57 ; F: \\
n=39 ; M: n=18\end{array}$ & $\begin{array}{l}\text { Trunk flexor:extensor } \\
\text { strength ratio imbalance } \\
\text { Females at increased risk for } \\
\text { injury }\end{array}$ & No studies found & NA \\
\hline $\begin{array}{l}\text { Retrospectively conducted } \\
\text { interviews with skiers training } \\
\text { at a development alpine ski } \\
\text { racing program over a } 6 \text {-year } \\
\text { period (response rate }=70 \% \text { ). }{ }^{29}\end{array}$ & $\begin{array}{l}\text { Total number of skiers } \\
\text { interviewed: } n=418 ; F \text { : } \\
n=231 ; \text {;: } n=187 \\
A C L \text { injuries: } n=65\end{array}$ & $\begin{array}{l}\text { Parents who suffered } A C L \\
\text { injury (odds ratio of } A C L \\
\text { injury if parents suffered } A C L \\
\text { injury }=1.95 \text { ) }\end{array}$ & No studies found & NA \\
\hline $\begin{array}{l}\text { Qualitative study with expert } \\
\text { stakeholders to identify injury } \\
\text { risk factors (not specific to } \\
\text { ACL injuries). }{ }^{66}\end{array}$ & $\begin{array}{l}\text { Total number of expert } \\
\text { stakeholders interviewed: } \\
n=6 \mathrm{I}\end{array}$ & $\begin{array}{l}\text { Top-4 perceived injury risk } \\
\text { factors (not specific to ACL } \\
\text { injuries): I) System ski, plate, } \\
\text { binding, boot; 2) Changing } \\
\text { snow conditions; 3) Speed } \\
\text { and course settings; and } \\
\text { 4) Physical aspects of skiers }\end{array}$ & $\begin{array}{l}\text { Equipment modification } \\
\text { to compare injury rates } \\
\text { in preequipment change } \\
\text { period (2006-20I2) to } \\
\text { post-equipment change period } \\
\text { (20I2-20I5); ski modification } \\
\text { includes increased sidecut } \\
\text { radius and ski length for all } \\
\text { disciplines (except slalom) }{ }^{75}\end{array}$ & $\begin{array}{l}\text { While overall } \\
\text { injuries } \\
\text { decreased, no } \\
\text { effect found on } \\
A C L \text { injuries }{ }^{75}\end{array}$ \\
\hline
\end{tabular}


While there is limited scientific data linking neuromuscular risk factors to ACL injury in elite alpine ski racers, sufficient hamstring vs quadriceps strength is thought to be important for ACL injury prevention in alpine ski racing. ${ }^{39,49,50,60,62,63}$ This may prove to be an important consideration as hamstring/quadriceps co-contraction is important for dynamic knee joint stabilization. ${ }^{35-37}$ Additionally, given the short time course of ACL injury in elite alpine ski racing, ${ }^{55}$ the RFD capacity of the hamstring/quadriceps muscles may be important as well..$^{50}$ While noninjured elite alpine ski racers may display marked bilateral hamstring/quadriceps strength symmetry, ${ }^{50,62}$ there are no studies to date linking a diminished hamstring/quadriceps strength ratio with increased risk of ACL injury. However, elite alpine ski racers who suffered an ACL injury produced peak hamstring torques at a more extended knee joint angle compared to their noninjured counterparts. ${ }^{39}$ Functional asymmetry testing has also been proposed as a potential screening tool for elite alpine ski racers. ${ }^{64}$ Currently, there are no studies showing a relationship between increased functional asymmetry and increased risk of ACL injury in ski racers, although adolescent alpine ski racers injured their left limb more frequently than their right limb. ${ }^{30}$ Whether this was related to limb dominance related to strength asymmetry could not be determined. ${ }^{30}$

Despite the lack of empirical data supporting a link between physical fitness and ACL injury risk, ${ }^{27,65,66}$ expert stakeholders identify physical factors in the top five of potential risk factors for alpine skiing injuries (Table 2). ${ }^{66}$ Skier fatigue was also identified as a highly ranked injury risk factor, ${ }^{66}$ and alpine ski racing injuries typically occur in the final sections of the race presumably when fatigue factors are more present. ${ }^{67}$ To account for this aspect of temporal build-up of fatigue, a fatiguing ski-specific jump test protocol was proposed to evaluate potential ACL related neuromuscular risk factors, such as increased functional interlimb asymmetry and potentially harmful shifts in quadriceps vs hamstring coactivity. ${ }^{68}$

Skier technique and tactics may also be identified as potential athlete related risk factors for injury in ski racing. ${ }^{66,69}$ Video analysis on the events leading to ACL injury in 20 skiers found that skiers were often out of balance and made tactical errors. ${ }^{54,69}$ Additionally, ACL injuries involving the landing back-weighted mechanism were preceded by poor skier jump technique and tactical errors. ${ }^{69}$ The ability to make tactical decisions is related to an athlete's psychological state and alpine skiers returning from injury/illness may be prone to poor decision-making at the return to sport transition. ${ }^{70}$ The effects of "injury contagion" or the consequences of a teammate's season ending injury on the mental well-being of elite alpine ski racers was also investigated due to the possibility that being witness to a serious injury may alter an alpine skier's confidence or tactical decision-making ability. ${ }^{71}$ However, no measurable effect was found. ${ }^{71}$

Finally, a genetic link appears to exist between adolescent alpine ski racers who suffer ACL injury and their parents (Table 2). ${ }^{72} \mathrm{~A}$ study evaluating the relationship between parents who suffered ACL injury in a group of 418 adolescent alpine ski racers found a significantly greater proportion of parental ACL injuries in the ACL injured group compared to the noninjured group. ${ }^{72}$ Most likely, this observation reflects that distinct anatomical features are inherited from parents to offspring, including various anatomical ACL injury risk factors such as a narrow intercondylar notch width, increased tibial plateau tilt angle, increased valgus angles, etc.

\section{Equipment risk factors}

Equipment variables are perceived as risk factors for injury in ski racing (Table 2). ${ }^{66}$ Expert ski coaches identified the aggressiveness of the skis and boots and the inability of ski racers to control their equipment as a key contributor to ACL injury. ${ }^{69}$ The ski side cut radius, ski length, ski bindings, and the stiffness of ski boots are all important equipment factors that are thought to be related to knee injury risk in ski racing. ${ }^{20,39-42,48,69}$ As the ski side cut radius decreases, the self-steering effect of skis increases, rendering them less controllable in an injury situation. ${ }^{56-59,66,69}$ Increasing the side cut radius of giant slalom skis by $33 \%$ reduced skier kinetic energy by $5 \% .{ }^{56}$ Longer skis provide more stability at high speeds, ${ }^{66}$ which is important as skier speed is also positively associated with increased injury risk. ${ }^{1,73}$

In fact, skier speed and the interaction between speed and jumps in the speed events were related to injury risk. ${ }^{73}$ Increasing ski length, decreasing ski width, and reducing the standing height (distance between ski base to binding plate cover) decreased skier kinetic energy during the steep sections of an alpine skiing course in expert alpine ski racers, which may be important for reducing skier speed, and thus minimizing injury risk. ${ }^{74}$ To reduce injuries, FIS changed the regulations for ski side cut radius for the 2012-2013 season. ${ }^{75}$ Side cut radius and ski length were increased for all disciplines except for slalom. ${ }^{75}$ While upper body injuries decreased, no statistically significant reduction in ACL injuries was found (Table 2). ${ }^{75}$

The ACL injury mechanism related to landing back weighted is thought to include anterior shear loading on the tibia resulting from the ski boot and a strong coupled 
eccentric-concentric quadriceps contraction as the skier recovers from the back-weighted position. ${ }^{41,54}$ Not only did a stiffer ski boot result in greater ACL loading during simulated ski landings but so did increased quadriceps muscle force. ${ }^{48} \mathrm{~A}$ combination of intrinsic contractile and anatomical factors as well as extrinsic factors from a stiff ski boot probably altogether make a complex contribution to ACL injury related to landing back weighted. ${ }^{48,49}$ However, it was noted that reducing ski boot stiffness may compromise alpine ski racing performance. ${ }^{48}$

Finally, the ski bindings may contribute to ACL injury risk. ${ }^{42,54,69}$ The ski bindings serve two purposes, namely, to release the ski if loading could potentially cause lower limb injury and to retain a rigid coupling between the boot and the ski. ${ }^{54}$ In $100 \%$ of slip-catch ACL injuries (ie, valgus/internal rotation mechanism), the ski either failed to release or released after the injury was sustained. ${ }^{54}$ The ability for ski bindings to differentiate between potentially injurious forces and normal forces encountered in ski racing may prove to be a significant challenge for ski binding design. ${ }^{54,69}$ Nevertheless, current research efforts are directed toward improved ski-binding-boot systems to reduce adverse injurious on the ACL. ${ }^{47}$

\section{Environmental risk factors}

Environmental factors including changing snow conditions, the course speed, and course settings are highly ranked among expert stakeholders as contributors to injury risk (Table 2). ${ }^{66}$ Further, expert alpine ski racing coaches highly ranked snow and course conditions as contributors to ACL injury in 20 cases including inconsistent and bumpy conditions, excessively challenging course sections that generate high speeds or compressions, poor visibility, or flat light and aggressive snow conditions (ie, hard dry snow that increases the risk of catching an edge). ${ }^{69}$ Skier speed resulting from the course design, jumps, and high force turns have also been linked with injury risk. ${ }^{1,73}$ It may be possible to reduce skier speed by altering the course design (eg, reducing gate distance),${ }^{76}$ although a substantial change in course design may be required for a meaningful reduction in skier speed. ${ }^{77}$ The effect of reducing skier speed on ACL injury risk remains unknown.

\section{$A C L$ injury prevention}

To the best of our knowledge, there have been no studies to date evaluating the effectiveness of ACL injury prevention training programs with elite alpine ski racers, and only a single study has evaluated the effects of changes to ski design on injury reduction. ${ }^{75}$ While the introduction of longer, less shaped skis was associated with an overall decrease in injuries, no reduction was found in ACL injuries among elite alpine ski racers. ${ }^{75}$ More research is required into modifications in equipment and slope course design to reduce the risk for ACL injury in alpine ski racing ${ }^{20,77}$ as ski bindings, boot stiffness, and steering ability (turn radius) of skis all contribute to ACL loading. ${ }^{44-48,56}$

In other sports with a high risk for ACL injury, injury prevention training programs have proved effective for reducing ACL injuries by improving neuromuscular risk factors associated with ACL injury. ${ }^{14,17-19,61,78,79}$ Interestingly, implementing an educational approach caused a $62 \%$ reduction in knee injuries in ski patrols who were shown videos of injury occurrences to increase awareness of technical and tactical contributors to the injury event. ${ }^{38}$ While tactical and technical errors are thought to contribute to ACL injuries in elite alpine ski racing, ${ }^{54,69}$ an educational approach for reducing ACL injuries among elite alpine ski racers has never been evaluated.

Neuromuscular injury prevention training programs may prove to be an effective method for reducing ACL injuries in alpine ski racing as skier fitness ${ }^{66}$ and fatigue-resistance ${ }^{66,67}$ are thought to be important factors for injury prevention. However, no link seems to exist between physical fitness variables and ACL injury risk, ${ }^{27,65}$ except for trunk strength in young ski racers. ${ }^{27}$ It seems important for ACL injury prevention and screening programs to have a high degree of specificity to the ACL injury mechanisms in ski racing. ${ }^{54}$ Based on the current data on ACL injury mechanisms in alpine ski racing, injury prevention training programs should address trunk control, ${ }^{46,54} \mathrm{knee} / \mathrm{hip}$ control (ie, tibial internal rotation, knee valgus, and hip internal rotation), ${ }^{54,55,69}$ functional lower-limb asymmetry, and hamstring/quadriceps muscle strength and RFD ratios. ${ }^{39}$

\section{Return to sport after $A C L$ injury and $A C L$ reinjury}

Only $55 \%$ of ACL injured athletes manage to return to preinjury performance levels after ACL reconstruction. ${ }^{80}$ Similar findings exist among professional football players where only $65 \%$ return to top-level sport participation following ACL injury. ${ }^{81}$ ACL injured ski racers have longer and more successful ski careers compared to those without ACL injury., 32 A 33-year retrospective study on French alpine ski racers found that 148 of the 477 ski racers who competed with the National team program for at least one season suffered an ACL injury. ${ }^{82}$ Notably, all skiers who suffered an ACL injury continued their career postinjury. Further, not only did the 
group of skiers with ACL injury have longer careers than the skiers in the noninjured group but also they achieved more podium finishes and higher international rankings. ${ }^{82}$ However, the age at which the ACL injury occurred was found to be an important determinant of the long-term outcome, with more favorable outcomes found for the younger ski racers. ${ }^{82}$

Despite the positive prognosis for ACL injured elite alpine ski racers, $19 \%$ of ACL reconstructed skiers suffered a reinjury to the same knee, while $31 \%$ suffered bilateral ACL rupture. ${ }^{3}$ This finding and the high-risk nature of alpine ski racing ${ }^{1,4,5}$ highlights the importance of functional assessments to determine a safe ski-specific return to sport progression following ACL injury. ${ }^{83}$ This is important as a medical professionals may rely only on a timeline based approach for returning athletes to sport after ACL reconstruction, despite that more objective functional measures are recommended. ${ }^{84}$ In other high-risk sports, functional testing post-ACL reconstruction including measures of asymmetry, postural balance, and hip/knee muscle control are predictive of ACL reinjury. ${ }^{85}$ Assessments of functional asymmetry, hamstring/quadriceps muscle strength ratios including RFD capacity, quadriceps vs hamstrings muscle coactivity, and fatigue-resistance of these neuromuscular factors have been proposed for elite alpine ski racers. ${ }^{50,64,68}$ Additionally, rehabilitation programs following ACL reconstruction should be ski-specific and account for the unique physical and technical demands of alpine ski racing. ${ }^{86}$ The skier's psychological readiness for return to sport is also important ${ }^{70,87}$ as ski racers may be prone to poor decision-making at the transition from rehabilitation to on snow training. ${ }^{70}$

Observational studies of elite alpine ski racers with/ without ACL reconstruction show that significant neuromuscular deficits persist despite return to sport. ${ }^{50,64,68}$ Deficits include increased interlimb functional asymmetry in vertical jump takeoff and landing, increased between-limb hamstring/quadriceps strength asymmetries, and decreased quadriceps vs hamstring muscle activity in jump takeoff and landing. ${ }^{50,64,68}$ The consequences of returning to alpine ski racing with these neuromuscular deficits are unknown, and it is unclear if specific neuromuscular changes may be characteristic of ACL reconstructed ski racers who successfully return after injury. To date, there are no links between these deficits and risk for ACL reinjury. However, ACL injury and the associated pathology including meniscal and chondral lesions are known to accelerate the progression of knee joint OA in young adults. ${ }^{7}$

Ski-specific ACL injury patterns have been demonstrated previously including increased prevalence of multiligament injuries especially to the medial collateral ligament (MCL). ${ }^{88-90}$ Due to the high-force injury mechanisms, the associated pathology with primary ACL tears in elite alpine ski racers may be significantly greater than in other sports including an increased prevalence of complex meniscal tears and chondral lesions. ${ }^{91} \mathrm{~A}$ high percentage of elite alpine racers also require additional surgery to address progression in meniscal and chondral lesions, and 2 years may be required for interlimb functional asymmetries to diminish to levels of noninjured alpine ski racers. ${ }^{91}$ Nevertheless, surgical repair of ACL tears and the associated knee joint injuries, respectively, is generally believed to lead to successful outcome for alpine ski racers. ${ }^{89,92}$

\section{Discussion}

Presently, the epidemiology and mechanisms of ACL injury are well described for elite alpine ski racers, and ACL injuries involving three distinct injury mechanisms occur frequently. ${ }^{1,4,26,53-55,69}$ To date, only two distinct risk factors for ACL injury have been identified, namely 1) reduced trunk flexion/extension strength in young ski racers, ${ }^{27}$ and 2) a genetic link in adolescent skiers. ${ }^{72}$ While modifications to the skis have reduced overall injury rates, no change in ACL injury rates was found for elite alpine ski racers. ${ }^{75}$ Apart from these factors, no other risk factors for ACL injury have been identified for alpine ski racers, and no published scientific studies exist on ACL injury prevention training programs. In female athletes, decreased $\mathrm{H} / \mathrm{Q}$ strength is associated with noncontact ACL injury, ${ }^{15}$ and female elite handball players who displayed a higher quadriceps vs hamstring muscle coactivity difference (ie, quadriceps dominance) were at increased risk of ACL injury. ${ }^{16}$ Functional asymmetries including increased knee abduction moments and valgus loading have also been associated with elevated ACL injury risk in female athletes. ${ }^{13}$ In other sports with a high risk for ACL injury, prevention programs have proved effective for reducing the incidence of ACL injury and to remove or reduce neuromuscular risk factors associated with ACL injury. ${ }^{14,17-19,61,78,79}$ Notably, neuromuscular injury prevention programs appear successful for reducing the relative risk of noncontact ACL injuries by more than $70 \%$ in high-risk athlete populations. ${ }^{78}$ Specific neuromuscular training programs focused on reducing high-risk lower limb biomechanics and improving lower limb motor control have been implemented as an adjunct to normal training, ${ }^{14}$ and as a warm-up prior to training and competition. ${ }^{18,19}$ Additionally, injury prevention programs may improve postural balance ${ }^{19}$ and diminish/remove the presence of specific neuromuscular 
and biomechanical risk factors related to ACL injury. ${ }^{79}$ The effectiveness of such programs appears to be heavily dependent on athlete compliance and consistency in performing the injury prevention training program. ${ }^{14,61}$

A main barrier to the implementation of ACL injury prevention training programs in alpine ski racing may be the paucity of scientific evidence on neuromuscular risk factors for ACL injury. On the other hand, it seems that the standard physical fitness testing regimes employed with elite alpine ski racers may not be specific enough to target the ACL injury mechanisms involved in alpine ski racing..$^{27,65}$ Also, the descriptive nature of previous studies on ACL injury mechanisms in alpine ski racing may prove challenging for identifying the contributing intrinsic neuromuscular risk factors for ACL injury. Biomechanical analysis of knee loading in alpine ski racing ${ }^{32-34,43-46}$ linked with analysis of the ACL injury mechanisms in alpine ski racing may provide important clues regarding potential modifiable neuromuscular risk factors for ACL injury, which may serve to improve the design of future injury prevention training programs. ${ }^{54,55}$ Further efforts should also be directed toward more specific and sensitive biomechanical and neuromuscular testing modalities than has been done to date. Such efforts may include assessments of trunk/hip/knee control during landing movements, functional asymmetry testing, hamstring/quadriceps muscle strength testing, and on-snow neuromuscular assessments given that such approaches have proven effective for identifying athletes at risk for ACL injury in other athlete populations. ${ }^{13,16}$ Future research on the reduction of adverse knee joint loading through ski-boot-binding system design and course design features also seems highly important. ${ }^{20,44-48,56-59,66,73-77}$ Based on the available evidence, it also appears that ACL injury prevention efforts could differ depending upon the skier performance level, including years of racing, ski racing discipline, and sex. ${ }^{1,3,27}$ At the highest performance level, ACL injury prevention efforts should be directed equally toward male and female ski racers due to the lack of sex-specific differences in ACL injury rates. ${ }^{26}$ However, among younger alpine ski racers, a specific focus on female alpine ski racers may be warranted. ${ }^{27}$ Thus, an important consideration might be to devise ACL injury prevention screening and programming according to specific subgroups of alpine ski racers. Developing ski-specific neuromuscular screening tests and prevention programs for ACL injury alongside prospectively designed studies to evaluate their effectiveness should be pursued. However, given the challenges around injury prevention research in athlete populations, such as small sample size, ${ }^{93}$ it may be necessary to use nonstandard statistical approaches ${ }^{94}$ and international scientific collaborations to adequately address these research questions.

Given the high occurrence of ACL reinjury, ${ }^{3}$ secondary injury prevention may be of equal importance as primary ACL injury prevention for alpine ski racers. Alpine ski racing is an extreme sport and involves a high incidence of traumatic injury. ${ }^{1,2,4}$ It seems critical to ensure that lower limb neuromuscular function is adequately restored following ACL injury and that skiers are fit to return to this high-risk activity. Currently, there are no generally accepted protocols for returning alpine ski racers back to snow after ACL injury. While recommendations have been made, ${ }^{50,64,68}$ the quality of the scientific evidence is limited to observational studies. In addition to appropriate neuromuscular testing protocols and on-snow progressions, the psychological readiness of skiers for risk taking should be considered in future scientific research efforts and should be included in return to sport assessments prior to unrestricted return to alpine ski racing. Currently, there are no scientific studies demonstrating a relationship between physical, functional, or psychological characteristics and risk for ACL reinjury in alpine ski racers. Yet, relationships between neuromuscular deficits and ACL reinjury have been identified in other athlete populations, ${ }^{21,84,85}$ and practitioners may be prone to relying solely on subjective criteria throughout the return to sport transition after ACL injury. ${ }^{84}$ For example, a comprehensive neuromuscular assessment following ACL injury predicted ACL reinjury with high sensitivity ${ }^{85}$ whereas a review of the scientific literature found that only $13 \%$ of studies reported using objective criteria for return to sport after ACL injury. ${ }^{84}$

A major consideration is the potential for ACL tears to be associated with injuries to knee structures other than the ACL, such as the menisci and articular cartilage. Such injuries have been reported to lead to the development of early knee joint OA in young athletes. ${ }^{7}$ It seems that alpine skiing-related ACL injury involves distinct injury patterns, ${ }^{89,90}$ and elite skiers may suffer a progressive worsening in chondral lesions and meniscal tears subsequent to primary ACL reconstruction. ${ }^{91}$ Ensuring that athletes have sufficient time to rehabilitate after ACL injury and that the associated injuries are given appropriate recovery time is important not only for achieving a safe return to the preinjury performance level but also with regard to promoting long-term health factors. ${ }^{20}$ Currently, the effects of ACL injury and injury to the associated knee structures on long-term health outcomes, such as the early development of knee OA, have not been investigated in an alpine ski racing population. Given the high likelihood that 
alpine ski racers will continue to race after primary ACL injury, ${ }^{82}$ future research should address this issue.

\section{Limitations}

While the main purpose of the present narrative review was to provide a summary of the scientific literature related to ACL injury/reinjury in alpine ski racing, there are potential limitations including bias in the article selection. We attempted to address this concern by providing a detailed account of paper selection process in the present review (Figure 1). Additionally, given the small number of studies providing higher quality scientific evidence on this topic, and the existence of mostly qualitative and descriptive studies, we were unable to undertake a quantitative systematic review. Nevertheless, the present review provides an overview of what is known around ACL injury/reinjury in alpine ski racing and also provides perspectives for future research.

\section{Conclusion}

In conclusion, epidemiological studies show that knee injuries and, more specifically, ACL tears are the most prevalent injury type in alpine ski racing and that these injuries result in a significant time loss from sport. The etiology of ACL injuries specifically around the injury event is well described, but there is limited scientific data on the internal neuromuscular factors involved in the injury process. Further, significant gaps in the scientific research exist around modifiable neuromuscular risk factors for ACL injury, and there are no studies to date that have implemented ACL injury prevention training programs in an alpine ski racing population. ACL reinjury is also prevalent in alpine ski racing, and alpine ski racers seem to have a disproportionately higher success rate for return to sport compared to other athlete populations. Nevertheless, neuromuscular deficits persist in ACL reconstructed elite alpine ski racers, and the long-term consequences of returning to sport after ACL injury on health outcomes such as the early development of knee joint OA remain unknown. Future research with unique study designs including international collaborations aimed at increasing sample sizes and the statistical power of ACL injury prevention investigations may be necessary to adequately address the gaps in the scientific literature.

\section{Disclosure}

The Alberta Innovates Health Solutions, the Killam Laureates, the Canada Research Chair Programme and the Killam Foundation provided funding for this research. The authors have no professional relationship with a for-profit company that would benefit from this research. The authors report no other conflicts of interest in this work.

\section{References}

1. Flørenes TW, Bere T, Nordsletten L, Heir S, Bahr R. Injuries among male and female World Cup alpine skiers. Br J Sports Med. 2009;43(13): 973-978.

2. Flørenes TW, Nordsletten L, Heir S, Bahr R. Injuries among world cup ski and snowboard athletes. Scand J Med Sci Sport. 2012;22(1):58-66.

3. Pujol N, Blanchi MP, Chambat P. The incidence of anterior cruciate ligament injuries among competitive alpine skiers: a 25-year investigation. Am J Sports Med. 2007;35(7):1070-1074.

4. Soligard T, Steffen K, Palmer-Green D, et al. Sports injuries and illnesses in the Sochi 2014 Olympic Winter Games. Br J Sports Med. 2015;49(7):441-447.

5. Stevenson H, Webster J, Johnson RJ, Beynnon BD. Gender differences in knee injury epidemiology among competitive alpine ski racers. Iowa Orthop J. 1998;18:64-66.

6. Viola RW, Steadman RJ, Mair SD, Briggs K, Sterett W. Anterior cruciate ligament injury incidence among male and female professional alpine skiers. Am J Sports Med. 1999;27(6):792-795.

7. Roos EM. Joint injury causes knee osteoarthritis in young adults. Curr Opin Rheumatol. 2005;17(2):195-200.

8. Hewett TE, Di Stasi SL, Myer GD. Current concepts for injury prevention in athletes after anterior cruciate ligament reconstruction. $\mathrm{Am} \mathrm{J}$ Sports Med. 2013;41(1):216-224.

9. van Mechelen W, Hlobil H, Kemper HC. Incidence, severity, aetiology and prevention of sports injuries. A review of concepts. Sports Med. 1992;14(2):82-99.

10. Meeuwisse WH. Asssessing causation in sport injury: a multifactorial model. Clin J Sport Med. 1994;4:166-170.

11. Bahr R, Holme I. Risk factors for sports injuries - a methodological approach. Br J Sports Med. 2003;37(5):384-392.

12. Alentorn-Geli E, Myer GD, Silvers HJ, et al. Prevention of non-contact anterior cruciate ligament injuries in soccer players. Part 1: mechanisms of injury and underlying risk factors. Knee Surg Sports Traumatol Arthrosc. 2009;17(7):705-729.

13. Hewett TE. Biomechanical measures of neuromuscular control and valgus loading of the knee predict anterior cruciate ligament injury risk in female athletes: a prospective study. Am J Sports Med. 2005; 33(4):492-501.

14. Myklebust G, Engebretsen L, Braekken IH, Skjølberg A, Olsen O-E, Bahr R. Prevention of anterior cruciate ligament injuries in female team handball players: a prospective intervention study over three seasons. Clin J Sport Med. 2003;13(2):71-78.

15. Zebis MK, Andersen LL, Bencke J, Kjaer M, Aagaard P. Identification of athletes at future risk of anterior cruciate ligament ruptures by neuromuscular screening. Am J Sports Med. 2009;37(10):1967-1973.

16. Myer GD, Ford KR, Barber Foss KD, Liu C, Nick TG, Hewett TE. The relationship of hamstrings and quadriceps strength to anterior cruciate ligament injury in female athletes. Clin J Sport Med. 2009;19(1): $3-8$.

17. Alentorn-Geli E, Myer GD, Silvers HJ, et al. Prevention of non-contact anterior cruciate ligament injuries in soccer players. Part 2: a review of prevention programs aimed to modify risk factors and to reduce injury rates. Knee Surg Sports Traumatol Arthrosc. 2009;17(8):859-879.

18. Bizzini M, Junge A, Dvorak J. Implementation of the FIFA 11+ football warm up program: how to approach and convince the Football associations to invest in prevention. Br J Sports Med. 2013;47(12): 803-806.

19. Bizzini M, Dvorak J. FIFA 11+: an effective programme to prevent football injuries in various player groups worldwide-a narrative review. Br J Sports Med. 2015;49(9):577-579.

20. Nagelli CV, Hewett TE. Should return to sport be delayed until 2 years after anterior cruciate ligament reconstruction? Biological and functional considerations. Sports Med. 2017;47(2):221-232.

21. Paterno MV, Rauh MJ, Schmitt LC, Ford KR, Hewett TE. Incidence of second ACL injuries 2 years after primary acl reconstruction and return to sport. Am J Sports Med. 2014;42(7):1567-1573. 
22. Spörri J, Kröll J, Gilgien M, Müller E. How to prevent injuries in alpine ski racing: what do we know and where do we go from here? Sports Med. Epub 2016 Aug 1.

23. Flørenes TW, Nordsletten L, Heir S, Bahr R. Recording injuries among World Cup skiers and snowboarders: a methodological study. Scand J Med Sci Sports. 2011;21(2):196-205.

24. Beynnon BD, Vacek PM, Newell MK, et al. The effects of level of competition, sport, and sex on the incidence of first-time noncontact anterior cruciate ligament injury. Am J Sports Med. 2014;42(8):1806-1812.

25. Prodromos CC, Han Y, Rogowski J, Joyce B, Shi K. A meta-analysis of the incidence of anterior cruciate ligament tears as a function of gender, sport, and a knee injury-reduction regimen. Arthrosc J Arthrosc Relat Surg. 2007;23(12):1320-1325.

26. Bere T, Flørenes TW, Nordsletten L, Bahr R. Sex differences in the risk of injury in World Cup alpine skiers: a 6-year cohort study. Br J Sports Med. 2014;48(1):36-40.

27. Raschner C, Platzer HP, Patterson C, Werner I, Huber R, Hildebrandt C. The relationship between ACL injuries and physical fitness in young competitive ski racers: a 10-year longitudinal study. Br J Sports Med. 2012;46(15):1065-1071.

28. Stenroos AJ, Handolin LE. Alpine skiing injuries in Finland - a two-year retrospective study based on a questionnaire among ski racers. $B M C$ Sports Sci Med Rehabil. 2014;6(9):2-6.

29. Hildebrandt $C$, Raschner $C$. Traumatic and overuse injuries among elite adolescent alpine skiers: a two-year retrospective analysis. Int Sport J. 2013;14(4):245-255.

30. Westin M, Alricsson M, Werner S. Injury profile of competitive alpine skiers: a five-year cohort study. Knee Surg Sports Traumatol Arthrosc. 2012;20(6):1175-1181.

31. Beynnon BD, Fleming BC. Anterior cruciate ligament strain in-vivo: a review of previous work. J Biomech. 1998;31(6):519-525.

32. Hame SL, Oakes D A, Markolf KL. Injury to the anterior cruciate ligament during alpine skiing: a biomechanical analysis of tibial torque and knee flexion angle. Am J Sports Med. 2002;30(4):537-540.

33. Herzog W, Read LJ. Lines of action and moment arms of the major force-carrying structures crossing the human knee joint. J Anat. 1993; 182:213-230

34. Bach JM, Hull ML. Strain of the anterior cruciate ligament increases linearly with quadriceps contraction. In: Johnson RJ, editor. Skiing Trauma and Safety. 12th ed. West Conshohocken, PA: American Society for Testing and Materials; 1999:94-104.

35. DeMorat G, Weinhold P, Blackburn T, Chudik S, Garrett W. Aggressive quadriceps loading can induce noncontact anterior cruciate ligament injury. Am J Sports Med. 2004;32(2):477-483.

36. Barrata R, Solomonow M, Zhou E, Letson D, Chuinard R, D'Ambrosia R. Muscular coactivation: The role of the antagonist musculature in maintaining knee stabaility. Am J Sports Med. 1988;16(2):113-122.

37. Solomonow M, Baratta R, Zhou E, et al. The synergistic action of the anterior cruciate ligament and thigh muscles in maintaining joint stability. Am J Sports Med. 1987;15(3):207-213.

38. Ettlinger CF, Johnson RJ, Shealy J. A method to help reduce the risk of serious knee sprains incurred in alpine skiing. Am J Sports Med. 1996;23(5):531-537.

39. Johnson S. Anterior cruciate ligament injury in elite alpine competitors. Med Sci Sports Exerc. 1995;27(3):323-327.

40. Maxwell SM, Hull ML. Measurement of strength and loading variables on the knee during alpine skiing. J Biomech. 1989;22(6-7):609-624.

41. McConkey JP. Anterior cruciate ligament rupture in skiing: a new mechanism of injury. Am J Sports Med. 1986;14(2):160-164.

42. Natri A, Beynnon BD, Ettinger CF, Johnson RJ, Shealy JE. Alpine ski bindings and injuries. Sports Med. 1999;28(1):35-48.

43. Herzog W, Read L. Anterior cruciate ligament forces in alpine skiing. J Appl Biomech. 1993;9(4):278-620.

44. Read L, Herzog W. External loading at the knee joint for landing movements in alpine skiing. Int J Sport Biomech. 1992;8(1):62-80.

45. Gerritsen KG, Nachbauer W, Van Den Bogert AJ. Computer simulation of landing movement in downhill skiing: anterior cruciate ligament injuries. J Biomech. 1996;29(7):845-854.
46. Heinrich D. Relationship between jump landing kinematics and peak ACL force during a jump in downhill skiing: a simulation study. Scand J Med Sci Sports. 2014;24(3):180-187.

47. Senner V, Michel FI, Lehner S, Brügger O. Technical possibilities for optimising the ski-binding-boot functional unit to reduce knee injuries in recreational alpine skiing. Sports Eng. 2013;16(4): 211-228.

48. Eberle R, Heinrich D, Kaps P, Oberguggenberger M, Nachbauer W. Effect of ski boot rear stiffness (SBRS) on maximal ACL force during injury prone landing movements in alpine ski racing: a study with a musculoskeletal simulation model. J Sports Sci. Epub 2016 Jul 26:1-9.

49. Barone M, Senner V, Schaff P. ACL injury mechanism in alpine skiing : analysis of an accidental ACL rupture. In: Johnson RJ, editor. Skiing Trauma and Safety. Vol 12. West Conshohocken, PA: American Society for Testing and Materials; 1999:63-81.

50. Jordan MJ, Aagaard P, Herzog W. Rapid hamstrings/quadriceps strength in ACL-reconstructed elite alpine ski racers. Med Sci Sports Exerc. 2015;47(1):109-119.

51. Zebis MK, Andersen LL, Ellingsgaard H, Aagaard P. Rapid hamstring/ quadriceps force capacity in male vs female elite soccer players. J Strength Cond Res. 2011;25(7):1989-1993.

52. Krosshaug T, Nakamae A, Boden BP, et al. Mechanisms of anterior cruciate ligament injury in basketball: video analysis of 39 cases. $\mathrm{Am}$ J Sports Med. 2007;35(3):359-367.

53. Krosshaug T, Slauterbeck JR, Engebretsen L, Bahr R. Biomechanical analysis of anterior cruciate ligament injury mechanisms: threedimensional motion reconstruction from video sequences. Scand J Med Sci Sports. 2007;17(5):508-519.

54. Bere T, Flørenes TW, Krosshaug T, et al. Mechanisms of anterior cruciate ligament injury in World Cup alpine skiing: a systematic video analysis of 20 cases. Am J Sports Med. 2011;39:1421-1429.

55. Bere T, Mok KM, Koga H, Krosshaug T, Nordsletten L, Bahr R. Kinematics of anterior cruciate ligament ruptures in World Cup alpine skiing: 2 case reports of the slip-catch mechanism. Am J Sports Med. 2013; 41:1067-1073.

56. Kröll J, Spörri J, Gilgien M, Schwameder H, Müller E. Sidecut radius and kinetic energy: equipment designed to reduce risk of severe traumatic knee injuries in alpine giant slalom ski racing. Br J Sports Med. 2016;50(1):20-25.

57. Kröll J, Spörri J, Gilgien M, Schwameder H, Müller E. Effect of ski geometry on aggressive ski behaviour and visual aesthetics: equipment designed to reduce risk of severe traumatic knee injuries in alpine giant slalom ski racing. Br J Sports Med. 2016;50(1):20-25.

58. Ruedl G, Webhofer M, Linortner I, et al. ACL injury mechanisms and related factors in male and female carving skiers: a retrospective study. Int J Sports Med. 2011;32(10):801-806.

59. Spörri J, Gilgien M, Schwameder H, Müller E. Sidecut radius and the mechanics of turning- equipment designed to reduce risk of severe traumatic knee injuries in alpine giant slalom ski racing. $\mathrm{Br} J$ Sports Med. 2016;50(1):20-25.

60. Murphy DF, Connolly DA, Beynnon BD. Risk factors for lower extremity injury: a review of the literature. $\mathrm{Br} J$ Sports Med. 2003; 37(1):13-29.

61. Steffen K, Meeuwisse WH, Romiti M, et al. Evaluation of how different implementation strategies of an injury prevention programme (FIFA 11+) impact team adherence and injury risk in Canadian female youth football players: a cluster-randomised trial. $\mathrm{Br} J$ Sports Med. 2013;47(8):480-487.

62. Neumayr G, Hoertnagl H, Pfister R, Koller A, Eibl G, Raas E. Physical and physiological factors associated with success in professional alpine skiing. Int J Sports Med. 2003;24(8):571-575.

63. White AT, Johnson SC. Physiological aspects and injury in elite alpine skiers. Sports Med. 1993;15(3):170-178.

64. Jordan MJ, Aagaard P, Herzog W. Lower limb asymmetry in mechanical muscle function: a comparison between ski racers with and without ACL reconstruction. Scand J Med Sci Sports. 2015;25(3): e301-e309. 
65. Schmitt K, Hörterer N, Vogt M, Frey WO, Lorenzetti S. Investigating physical fitness and race performance as determinants for the ACL injury risk in Alpine ski racing. BMC Sports Sci Med Rehabil. 2016:8:23.

66. Spörri J, Kröll J, Amesberger G, Blake OM, Müller E. Perceived key injury risk factors in World Cup alpine ski racing - an explorative qualitative study with expert stakeholders. Br J Sports Med. 2012;46(15): 1059-1064.

67. Bere T, Flørenes TW, Krosshaug T, et al. A systematic video analysis of 69 injury cases in World Cup alpine skiing. Scand J Med Sci Sport. 2014;24(4):667-677.

68. Jordan MJ, Aagaard P, Herzog W. Asymmetry and thigh muscle coactivity in fatigued ACL-reconstructed elite skiers. Med Sci Sports Exerc. 2017;49(1):11-20.

69. Bere T, Florenes TW, Krosshaug T, Nordsletten L, Bahr R. Events leading to anterior cruciate ligament injury in World Cup alpine skiing: a systematic video analysis of 20 cases. Br J Sports Med. 2011;45(16): 1294-1302.

70. Bianco T, Malo S, Orlick T. Sport injury and illness: elite skiers describe their experiences. Res Q Exerc Sport. 1999;70(2):157-169.

71. O'Neill DF. Injury contagion in Alpine ski racing: the effect of injury on teammates' performance. J Clin Sport Psychol. 2008;2(3):278-292.

72. Westin M, Reeds-Lundqvist S, Werner S. The correlation between anterior cruciate ligament injury in elite alpine skiers and their parents. Knee Surg Sports Traumatol Arthrosc. 2016;24(3):697-701.

73. Gilgien M, Spörri J, Kröll J, Crivelli P, Müller E. Mechanics of turning and jumping and skier speed are associated with injury risk in men's World Cup alpine skiing: a comparison between the competition disciplines. Br J Sports Med. 2014;48(9):742-747.

74. Gilgien M, Spörri J, Kröll J, Müller E. Effect of ski geometry and standing height on kinetic energy: equipment designed to reduce risk of severe traumatic injuries in alpine downhill ski racing. Br J Sports Med. 2016;50(1):8-13

75. Haaland B, Steenstrup SE, Bere T, Bahr R, Nordsletten L. Injury rate and injury patterns in FIS World Cup Alpine skiing (2006-2015): have the new ski regulations made an impact? Br J Sports Med. 2016;50(1):32-36.

76. Gilgien M, Crivelli P, Spörri J, Kröll J, Müller E. Characterization of course and terrain and their effect on skier speed in World Cup alpine ski racing. PLoS One. 2015;10(3):e0118119.

77. Sporri J, Kroll J, Schwameder H, et al. Course setting and selected biomechanical variables related to injury risk in alpine ski racing: an explorative case study. Br J Sports Med. 2012;46(15):1072-1077.

78. Sugimoto D, Myer GD, McKeon JM, Hewett TE. Evaluation of the effectiveness of neuromuscular training to reduce anterior cruciate ligament injury in female athletes: a critical review of relative risk reduction and numbers-needed-to-treat analyses. $\mathrm{Br} J$ Sports Med. 2012;46(14):979-988.

79. Zebis MK, Andersen LL, Brandt M, et al. Effects of evidence-based prevention training on neuromuscular and biomechanical risk factors for ACL injury in adolescent female athletes: a randomised controlled trial. Br J Sports Med. 2016;50(9):552-557.
80. Ardern CL, Taylor NF, Feller JA, Webster KE. Fifty-five per cent return to competitive sport following anterior cruciate ligament reconstruction surgery: an updated systematic review and meta-analysis including aspects of physical functioning and contextual factors. Br J Sports Med. 2014;48:1543-1552.

81. Waldén M, Hägglund M, Magnusson H, Ekstrand J. ACL injuries in men's professional football: a 15 -year prospective study on time trends and return-to-play rates reveals only $65 \%$ of players still play at the top level 3 years after ACL rupture. Br J Sports Med. 2016;50(12):744-750.

82. Haida A, Coulmy N, Dor F, et al. Return to sport among French alpine skiers after an anterior cruciate ligament rupture: results from 1980 to 2013. Am J Sports Med. 2016;44(2):324-330.

83. Jordan MJ, Aagaard P, Herzog W. A return to skiing envelope of function for anterior cruciate ligament reconstructed elite Alpine ski racers. In: Muller E, Kroll J, Lindinger S, Pfusterschmied J, Stoggle T, editors. Science and Skiing VI. Salzburg, Austria: Meyer \& Meyer Sport; 2015:187-195.

84. Barber-Westin SD, Noyes FR. Factors used to determine return to unrestricted sports activities after anterior cruciate ligament reconstruction. Arthroscopy. 2011;27(12):1697-1705.

85. Paterno M V, Schmitt LC, Ford KR, et al. Biomechanical measures during landing and postural stability predict second anterior cruciate ligament injury after anterior cruciate ligament reconstruction and return to sport. Am J Sports Med. 2010;38(10):1968-1978.

86. Kokmeyer D. Suggestions from the field for return-to-sport rehabilitation following anterior cruciate ligament reconstruction: alpine skiing. J Orthop Sports Phys Ther. 2012;42(4):313-326.

87. Nordahl B, Sjöström R, Westin M, Werner S, Alricsson M. Experiences of returning to elite alpine skiing after ACL injury and ACL reconstruction. Int J Adolesc Med Health. 2014;26(1):69-77.

88. Granan L, Inacio M. Sport-specific injury pattern recorded during anterior cruciate ligament reconstruction. Am J Sports Med. 2013 41(12):2814-2818.

89. Higgins R, Steadman J. Anterior cruciate ligament repairs in world class skiers. Am J Sports Med. 1987;15(5):439-447.

90. Pressman A, Johnson DH. A review of ski injuries resulting in combined injury to the anterior cruciate ligament and medial collateral ligaments. Arthroscopy. 2003;19(2):194-202.

91. Jordan MJ, Heard M, Doyle-Baker T, Aagaard P, Herzog W. Associated Pathology and Limb Asymmetry in ACL Reconstructed Elite Alpine Racers. In: Mueller E, editor. Abstract Book of the 7th International Congress on Science and Skiing. Salzburg, Austria: Department of Sport Science and Kinesiology University of Salzburg, Austria; 2016:114.

92. Ekeland A, Vikne J. Treatment of acute combined knee instabilities and subsequent sport performance. Knee Surg Sports Traumatol Arthrosc. 1995;3:180-183.

93. Bahr R. Why screening tests to predict injury do not work-and probably never will: a critical review. Br J Sports Med. 2016;50(13):776-780.

94. Bittencourt NF, Meeuwissie W, Mendonca LD, Nettel-Aguirre A, Ocarino JM, Fonseca ST. Complex systems approach for sports injuries: moving from risk factor identification to injury pattern recognition-narrative review and new concept. Br J Sports Med. Epub 2016 Jul 21.
Open Access Journal of Sports Medicine

\section{Publish your work in this journal}

The Open Access Journal of Sports Medicine is an international, peer-reviewed, open access journal publishing original research, reports, reviews and commentaries on all areas of sports medicine. The journal is included on PubMed. The manuscript management system is completely online and includes a very quick and fair

\section{Dovepress}

peer-review system. Visit http://www.dovepress.com/testimonials.php to read real quotes from published authors 